\title{
REFLEXÕES SOBRE A TEORIA ECONÔMICA DA INOVAÇÃO. BREVE HISTORICIZAÇÃO DA DIALÉTICA ENTRE CIÊNCIA E TECNOLOGIA.
}

\section{Heitor Antunes Milhomens*}

RESUMO: Este artigo objetiva ser uma revisão teórica da economia da inovação e suas raízes históricas, de modo a pontuar importantes considerações sobre a construção do conceito contemporâneo de inovação, historicamente forjado ao longo de séculos. O objetivo é sintetizar algumas das mais importantes formulações teóricas e históricas das ciências econômicas no que se refere ao estudo da inovação tecnológica, historicizando a dialética entre ciência e tecnologia, permitindo-nos entender como este binômio torna-se um sustentáculo do crescimento econômico dos Séculos XIX, XX e XXI, atraindo a atenção dos estados modernos, que passam a normatizar formas de incentivá-lo.

PALAVRAS-CHAVE: Direito; Ciência; Tecnologia; Inovação; Historicização.

\section{REFLECTIONS ON THE ECONOMIC THEORY OF INNOVATION. BRIEF HISTORICIZATION OF DIALETICS BETWEEN SCIENCE AND TECHNOLOGY.}

ABSTRACT: This article aims to be a theoretical review of the economics of innovation and its historical roots, in order to point out important considerations about the construction of the contemporary concept of innovation, historically forged over centuries. The objective is to synthesize some of the most important theoretical and historical formulations of the economic sciences regarding the study of technological innovation, historicizing the dialectic between science and technology, allowing us to understand how this binomial becomes a support for the economic growth of the centuries, attracting the attention of modern states, which now standardize ways of encouraging it.

KEY WORDS: Right. Science. Technology. Innovation. Historicization.

\section{INTRODUÇÃO.}

O estudo proposto nas linhas que seguem objetiva ser uma revisão teórica da economia da inovação e suas raízes históricas, de modo a pontuar importantes considerações sobre a construção do conceito contemporâneo de inovação, historicamente forjado ao longo de séculos. O objetivo é sintetizar aos estudiosos das ciências jurídicas algumas das mais importantes formulações teóricas e históricas das ciências econômicas no que se refere ao estudo da inovação tecnológica.

\footnotetext{
* É mestrando em Direito pelo PPGD/ICJ/UFPA. Possui LL.M. em Direito Empresarial pela Fundação Getúlio Vargas - FGV (2014) e graduação em Direito pelo Centro Universitário do Estado do Pará - CESUPA (2009). Tem experiência na área de Direito, com ênfase em Direito Civil, Direito do Consumidor, Direito Empresarial, Propriedade Intelectual e Direito Tributário. E-mail: heitormil@gmail.com.
} 
Para desenvolver tal estudo, inicialmente buscamos sintetizar a teoria econômica da inovação, tal como formulada por Joseph Schumpeter e posteriormente aperfeiçoadas por autores neoschumpterianos e acolhida por organimos internacionais.

Em seguida, destinam-se tópicos a tecer uma breve historicização da dialética entre ciência e tecnologia, permitindo-nos entender como este binômio torna-se um sustentáculo do crescimento econômico dos Séculos XIX, XX e XXI, atraindo a atenção dos estados modernos, que passam a normatizar formas de incentivá-lo. Tal historização se dá a partir das obras fundamentais de Donald Stokes (2005) e Nathan Rosemberg (2006), dois dos mais proeminentes economistas contemporâneos que se debruçam sobre o tema da inovação tecnológica

Aportamos, ainda, algumas considerações sobre a militarização do conhecimento científico e a crise ambiental enquanto risco do desenvolvimento, a fim de robustecer as reflexões sobre o tema.

Ao fim, propomos algumas problematizações que ainda devem ser enfrentadas pelas ciências jurídicas como forma de enfrentar o futuro da ciência e tecnologia na construção do desenvolvimento sustentável.

Para percorrer o trajeto de pesquisa acima proposto, utiliza-se o método lógicodedutivo apoiado na revisão bibliográfica.

\section{A TEORIA ECONÔMICA DA INOVAÇÃO.}

Os últimos 250 anos são apenas um grão de areia na longa história do homem moderno, o homo sapiens, que surgiu na África Equatorial há cerca de 200.000 e 150.000 anos atrás, e partiu para dominar todos os continentes do globo terrestre, utilizando-se de sua inteligência para desenvolver ferramentas e tecnologias primitivas que permitiram dominar o fogo, subjugar e exterminar as demais espécies de hominídeos, desenvolver a agricultura e a pecuária e formar os primeiros conglomerados urbanos.

Apesar de recentes, as mudanças tecnológicas desenvolvidas neste pequeno período histórico, desde a Revolução Industrial no Século XVIII, até a atual Revolução Digital, causada pelo boom da microcomputação e da tecnologia da informação a partir da década de 1980 e se intensificando cada vez mais no século XXI, são sensíveis e mudaram radicalmente as estruturas das relações entre o homem e o meio ambiente, numa escala nunca experimentada pela raça humana. 
O domínio das ciências naturais, a partir das suas três disciplinas basilares - a química, a física e a biologia -, apoiado no modelo econômico liberal e na globalização, gerou cada vez mais a especialização do conhecimento científico que desencadeou no desenvolvimento da energia elétrica, das telecomunicações, conquista aeroespacial, engenharia genética, desenvolvimento da microcomputação, robótica, nanotecnologia, dentre tantos outros maravilhosos conhecimentos que vemos nascer a cada dia, em um ritmo frenético, em centros tecnológicos que reúnem as mais brilhantes mentes científicas da humanidade, como o Vale do Silício, lar das mais proeminentes indústrias de alta tecnologia.

A inovação é a palavra de ordem. Promovida no ambiente público e privado, a ideia de inovação se tornou o santo graal dos administradores e economistas no século XXI, gerando riquezas e movimentando cifras exorbitantes na economia mundial.

A economia da inovação industrial está alicerçada nos estudos do grande economista austríaco Joseph A. Schumpeter (1997), para quem a inovação é o "fenômeno fundamental" da vida econômica capitalista. É a partir da inovação que se gera o desenvolvimento, o progresso e o crescimento econômico. Noutras palavras, em nossa sociedade o desenvolvimento econômico é meramente um fruto da inovação.

Na sua visão, o produtor de tecnologia é o protagonista do desenvolvimento econômico, pois é o agente que o inova no mercado e traz uma nova demanda de consumo para um produto que, muitas vezes, era desconhecido e que os consumidores sequer sentiam a necessidade de sua aquisição, até observar os confortos e melhorias que este determinado produto pode implementar em sua vida e assim querê-lo para si:

as inovações no sistema econômico não aparecem, via de regra, de tal maneira que primeiramente as novas necessidades surgem espontaneamente nos consumidores e então o aparato produtivo se modifica sob sua pressão. Não negamos a presença desse nexo. Entretanto, é o produtor que, via de regra, inicia a mudança econômica, e os consumidores são educados por ele, se necessário; são, por assim dizer, ensinados a querer coisas novas, ou coisas que diferem em um aspecto ou outro daquelas que tinham o hábito de usar. (SCHUMPETER, 1997, p.76)

A respeito deste raciocínio, com precisão sintetiza Viggiani $(2015$, p. 64):

Schumpeter acredita ser a inovação um agente de ruptura no sistema econômico, sendo a inovação tecnológica definida como a implementação de novos produtos ou processos, ou ainda mudanças significativas em produtos ou processos já existentes. Assim, a inovação pode ser considerada radical, quando se trata de um novo produto, processo ou forma de organização completamente nova ou incremental, quando apenas são realizadas melhorias em produtos, processos ou formas de organização pré-existentes. 
Através de sua teoria, Schumpeter propõe uma abordagem baseada nas "novas combinações" ou inovações ${ }^{l}$, através do qual se realiza o desenvolvimento. Vejamos como ele descreve este fenômeno em sua obra:

Produzir significa combinar materiais e forças que estão ao nosso alcance (cf. capítulo I). Produzir outras coisas, ou as mesmas coisas com método diferente, significa combinar diferentemente esses materiais e forças. Na medida em que as "novas combinações" podem, com o tempo, originar-se das antigas por ajuste contínuo mediante pequenas etapas, há certamente mudança, possivelmente há crescimento, mas não um fenômeno novo nem um desenvolvimento em nosso sentido. Na medida em que não for este o caso, e em que as novas combinações aparecerem descontinuamente, então surge o fenômeno que caracteriza o desenvolvimento. Por motivo da conveniência de exposição, quando falarmos em novas combinações de meios produtivos, só estaremos nos referindo doravante ao último caso. O desenvolvimento, no sentido que lhe damos, é definido então pela realização de novas combinações. (SCHUMPETER, 1997, p. 76)

Dessa forma, na teoria schumpeteriana, não podemos trabalhar a ideia de inovação dissociada do fenômeno principal que a mesma provoca: o desenvolvimento.

Por “novas combinações”, Schumpeter (1997, p. 76) lista as seguintes hipóteses:

1) Introdução de um novo bem - ou seja, um bem com que os consumidores ainda não estiverem familiarizados - ou de uma nova qualidade de um bem. 2) Introdução de um novo método de produção, ou seja, um método que ainda não tenha sido testado pela experiência no ramo próprio da indústria de transformação, que de modo algum precisa ser baseada numa descoberta cientificamente nova, e pode consistir também em nova maneira de manejar comercialmente uma mercadoria. 3) Abertura de um novo mercado, ou seja, de um mercado em que o ramo particular da indústria de transformação do país em questão não tenha ainda entrado, quer esse mercado tenha existido antes, quer não. 4) Conquista de uma nova fonte de oferta de matérias-primas ou de bens semimanufaturados, mais uma vez independentemente do fato de que essa fonte já existia ou teve que ser criada. 5) Estabelecimento de uma nova organização de qualquer indústria, como a criação de uma posição de monopólio (por exemplo, pela trustificação) ou a fragmentação de uma posição de monopólio. (grifei)

Para os teóricos da inovação, não há caminho mais certo para o desenvolvimento de um país (geração de conhecimento e tecnologia) que a inovação. Todavia, para alcançá-la, é necessário que se observe o rigor do processo de Pesquisa e Desenvolvimento - P\&D. Nesse sentido, o Manual de Frascati² (OCDE, 2013, p. 23), nos ensina que:

21. As atividades de inovação tecnológica são o conjunto de diligências científicas, tecnológicas, organizacionais, financeiras e comerciais, incluindo o investimento em novos conhecimentos, que realizam ou destinam-se a levar à realização de produtos e processos tecnologicamente novos e melhores. P\&D é apenas uma dessas atividades e pode ser realizada em diferentes estágios do processo de inovação, sendo usada não apenas como uma fonte de ideias inventivas, mas também para resolver os problemas que possam surgir em qualquer etapa do processo, até a sua conclusão. 22. Além disso, $P \& D$ pode ser diferenciada de outras áreas de atividades criativas no processo de inovação. Conforme definido no Manual de Oslo (OCDE, 1997), P\&D é a aquisição de tecnologia e know-how não incorporados, a aquisição de tecnologia incorporada, ferramentas e engenharia industrial, o estudo de concepção industrial (não classificado em outros lugares), a aquisição de

\footnotetext{
${ }^{1}$ Podemos tratar ambas as expressões como sinônimos na obra de Schumpeter.

${ }^{2}$ O Manual de Frascati é um documento da ORGANIZAÇÃO PARA COOPERAÇÃO E DESENVOLVIMENTO ECONÔMICO - OCDE que traz a metodologia para o fomento da Pesquisa e Desenvolvimento. Suas definições são acatadas por diversos países e seus princípios utilizados como base para diversas leis de incentivo econômico.
} 
outros equipamentos, o início da produção e da comercialização de produtos tecnologicamente novos e melhores.

Ainda nos termos do Manual Frascati, o processo de P\&D compreende: a pesquisa básica, a pesquisa aplicada e o desenvolvimento experimental. Vejamos:

64. [...] A pesquisa básica consiste em trabalhos experimentais ou teóricos desenvolvidos principalmente com a finalidade de adquirir novos conhecimentos sobre os fundamentos de fenômenos e fatos observáveis, sem considerar uma aplicação ou uso particular. A pesquisa aplicada consiste igualmente em trabalhos originais empreendidos com o objetivo de adquirir novos conhecimentos. No entanto, ela é principalmente direcionada a um objetivo prático determinado. $\mathrm{O}$ desenvolvimento experimental consiste em trabalhos sistemáticos com base em conhecimentos existentes obtidos pela pesquisa ou experiência prática, para lançar a fabricação de novos materiais, produtos ou dispositivos, para estabelecer novos procedimentos, sistemas e serviços ou para melhorar os já existentes em $P \& D$. Inclui tanto a $P \& D$ formal quanto a $P \& D$ informal ou ocasionalmente outras unidades. (OCDE, 2013, p. 38)

Pesquisa básica é, portanto, a investigação fundamental para se compreender um fenômeno, não sendo esperado que dela se produza um efeito prático. Ao seu turno, a pesquisa aplicada é uma investigação original, idealizada em função de se obter um objetivo prático. Busca-se, portanto, que os conhecimentos ou informações resultantes da pesquisa aplicada gerem patentes ou outros bens protegidos por propriedade intelectual.

Donald Stokes (2005. p. 39) preleciona a esse respeito:

Se a pesquisa fundamental pode ser diretamente influenciada por objetivos aplicados, então a ciência básica não pode mais ser vista apenas como uma remota geradora de descobertas científicas, movidas à curiosidade, descobertas a serem posteriormente convertidas em novos produtos e processos pela pesquisa aplicada e pelo desenvolvimento, nos estágios subsequentes da transferência tecnológica. Essa constatação, porém, apenas prepara o cenário para uma consideração mais realista da relação entre ciência básica e a inovação tecnológica.

Para os teóricos neoschumpterianos a inovação não surge pronta para a sua apresentação ao mercado de consumo. Antes, ela se funda sobre novos princípios e concepções, cuidadosamente desenvolvidas através da pesquisa básica ou aplicada. No cenário mundial podemos observar que todo os países, sobretudo os mais ricos, apoiam as atividades de inovação seja através de financiamento direto, incentivos fiscais ou subsídios à cadeia de produção.

Para os teóricos da inovação, esse fenômeno se dá por uma razão muito clara: os riscos nos investimentos em inovação são enormes, frequentemente injetam-se dispendiosos recursos em $P \& D$ que não resultam em uma certeza de retorno do investimento. Todavia, uma vez alcançado os objetivos, seus benefícios são igualmente enormes, gerando frutos para toda a sociedade. Em outras palavras, aduzem que a inovação tecnológica gera externalidades positivas à sociedade, que devido a falhas de mercado não são devidamente recompensados, 
havendo, assim, a necessidade do Estado promover e incentivar as atividades de ciência, tecnologia e inovação.

Nesse sentido, Sherwood (1992, p. 90) é categórico ao afirmar que:

em comparação com outros fatores, a injeção de tecnologia nova parece produzir uma taxa muito alta de retorno social. Em outras palavras, o benefício recebido pela sociedade em geral em decorrência do investimento em inovação parece ser muito grande.

Aponta-se que os países que mais investem em inovação apresentam crescimentos robustos e duradouros ao longo de décadas. Diversos economistas corroboram este entendimento. Ao estuda-los, Eva Stal (2007, p. 23-53) demonstra que:

Dentre os trabalhos, destaca-se o estudo de Fagerberg (1988), que analisou o PIB per capita, os gastos em P\&D como percentual do PIB e o numero de patentes externas por bilhão de dólares exportados. Os resultados mostram que existe uma relação positiva entre PIB per capita e atividade tecnológica, medida tanto pelos gastos em $\mathrm{P} \& \mathrm{D}$ quanto pelo número de patentes.

A partir desta e de outras conclusões de estudos econômicos relevantes, os países em desenvolvimento passaram a buscar estruturar o seu ordenamento jurídico para implementar formas de incentivo à inovação, criando e, sobretudo, estruturando um Sistema Nacional de Inovação confiável.

Entretanto, apesar da aparente atualidade que a palavra inovação invoca, antes de adentrar na esfera da estruturação de um ordenamento jurídico para promovê-la e incentivá-la, precisamos compreender como o próprio conceito de inovação foi historicamente forjado ao longo de séculos.

\section{BREVE HISTORICIZAÇÃO DA DIALÉTICA ENTRE CIÊNCIA E TECNOLOGIA.}

Para que possamos entender o que é a inovação e como ela surge, precisamos, antes, refletir sobre a sutil interação entre a ciência e tecnologia, bem como as consequências desta interação na vida humana.

A relação dialética entre ciência e tecnologia, embora fortemente presente e consolidado na sociedade capitalista - ao menos desde a Revolução Industrial -, não tem merecido a devida atenção das ciências sociais. Apenas alguns aspectos desta relação tem sido, há algum tempo, objeto de interesse contumaz da literatura econômica: o ritmo de melhoria da produtividade, o progresso da aprendizagem decorrente dos avanços em ciência e tecnologia, o fluxo e velocidade com que ocorre a transferência de tecnologia no mercado e, com maior frequência, as formas como as políticas governamentais podem influenciar, através de incentivos e subvenções, os empreendedores e a comunidade científica para o 
desenvolvimento de pesquisas e técnicas que resultem em inovação de produtos e processos em determinadas áreas, eleitas como estratégicas pelos agentes públicos.

Embora de extrema relevância para o mundo em que vivemos, o prisma econômico não pode ser a única lente voltada à temática da interação entre ciência e tecnologia, uma vez que míope para tratar de certos temas que lhe são subjacentes. Neste sentido, defendo a necessária ampliação deste estudo pelas demais ciências sociais - e em específico a ciência jurídica -, para que possamos apreender as intrínsecas relações destas duas racionalidades enquanto um fenômeno histórico que é, em grande parte, responsável pelo estabelecimento de particularidades nas relações humanas que caracterizam a sociedade neoliberal que adentrou o século XXI e o seu culto pela inovação como a solução para todas as mazelas sociais e ambientais.

Questões relacionadas à saturação do meio ambiente artificial e esgotamento de bens da natureza, a precariedade no desenvolvimento humano dos países periféricos, o surgimento de novas doenças da modernidade - que atingem a saúde física e psicológica - nos países mais ricos, a crescente substituição das experiências naturais e das relações interpessoais por uma convivência em um meio ambiente digital e a precarização das relações humanas são exemplos de problemas que passaram a existir ou foram agravados a partir dos avanços possibilitados pela interação dual entre ciência e tecnologia, mas que não são enfrentados pela ciência econômica e para os quais esta não está apta à apresentar respostas - ao menos de forma isolada -, por fugirem ao seu escopo de estudo.

Esclareço que compreender as interações entre ciência e tecnologia enquanto um fenômeno histórico não é uma proposição exatamente nova. Conforme aponta Rosenberg (2006, p.9), esta análise remonta aos estudos de Marx que, entretanto "abriu caminhos para os estudos dos domínios da tecnologia pelos quais, posteriormente, quase ninguém passou”, até ser retomada de forma mais estruturada pelo próprio Rosenberg, a partir do quarto final do Século XX, e que ganhou valioso aporte com os estudos de Stokes (2005), já ao final da década de 1990.

Utilizo tais referências por acreditar que a análise da interação entre ciência e tecnologia apresenta-se como um ângulo de observação privilegiado para compreender questões que conformaram a própria estrutura da sociedade capitalista neoliberal em que vivemos, alicerçando seus fundamentos e projetando seus horizontes. 
A racionalidade científica que caracteriza o Século XXI, com orientação marcadamente eurocêntrica, tem uma origem que pode ser claramente determinada: a filosofia clássica. A investigação científica é uma invenção grega que remonta aos filósofos de Mileto dos séculos VI e V a.C., orientados pela crença de que uma investigação racional poderia fornecer um entendimento geral da natureza e seus fenômenos. Para tanto, o pensador deveria libertar-se das atividades práticas - desenvolvimento de técnicas para lidar com problemas e obstáculos do cotidiano - para concentrar-se no estudo da arte, da investigação filosófica. Este modelo de investigação científica possibilitou, por exemplo, o desenvolvimento da geometria de Pitágoras e Euclides e da teoria atômica de Demócrito (STOKES, 2005, p. 52-53).

Esta evolução no conhecimento científico seu deu não sem alguma segregação social. Nesse sentido, a própria arquitetura da República ideal de Platão separava radicalmente as pessoas entres os cidadãos plutocráticos, empenhadas no estudo da filosofia e na condução do Estado, dos escravos e outras pessoas de menor posição social, dedicados ao trabalho manual e atividades práticas do dia-a-dia. A partir desta divisão social do trabalho, criou-se a cultura de que o pensador deveria buscar o conhecimento como um fim em si mesmo, como signo de distinção e superioridade. Nesse sentido, ao definir o sábio, Aristóteles (2002, p. 9) em sua Metafísica, afirma que:

reputamos sábio quem é capaz de conhecer as coisas difíceis ou não facilmente compreensíveis
para o homem (de fato, o conhecimento através dos sentidos é comum a todos e, por ser fácil, não
é sapiência). Mais, ainda, reputamos que, em cada ciência, seja mais sábio quem possui maior
conhecimento das causas e quem é mais capaz de ensiná-la aos outros. Consideramos ainda, entre
as ciências, que seja em maior grau de sapiência aquela que é escolhida por si e unicamente em
vista do saber, em contraste com a que é escolhida em vista do que dela deriva. ${ }^{3}$ [sem grifos no
original]

Com base nesta distinção qualitativa do conhecimento, aquele que era devotado a si próprio como fim último - o conhecimento filosófico ou científico como hoje o conhecemos foi alçado à categoria de arte; enquanto que o conhecimento ordinário, de viés utilitário e preocupado com a solução de problemas da rotina, de trazer facilidades e comodidades ao homem, passou a ser entendido como técnica. Tal distinção aprofundou-se no pensamento grego ao longo do seu período clássico e chegou à Roma, onde também exerceu grande influência sobre a divisão social do trabalho, até o fim da Antiguidade.

Em linhas gerais, esta filosofia científica de matriz grega ficou congelada, ao menos no continente europeu, durante a Alta e Baixa Idade Média, até que tornou-se disponível para

\footnotetext{
${ }^{3}$ ARISTÓLETES. Metafísica, Livro A, Parte 2, linhas 10-17.
} 
a sociedade europeia em torno do final da Idade Média, com a redescoberta da filosofia clássica que "serviu como estímulo inicial à criação das novas universidades em Oxford, Paris, Bolonha e Pádua, todas as quais reservaram espaços em seus currículos para a nova ciência”, sem a qual seria difícil imaginar o florescimento da Revolução Científica (STOKES, 2005, p. 57).

As transformações sociais geradas durante a Idade Média, entretanto, possibilitaram sensíveis mudanças na forma clássica de dedicar-se à arte do conhecimento. Uma nova divisão social do trabalho possibilitou aos artesãos dedicados à solução de problemas práticos - organizados através das corporações de ofício - a ocupar uma posição social diferente daquela que era reservada aos seus antecessores do mundo grego. Paralelamente, a doutrina cristã conferiu um novo valor ao trabalho manual. Tais fatores parecem ter sido determinantes para que, apesar da cultura de superioridade da ciência pura profundamente arraigada na tradição científica, os cientistas europeus desenvolvessem uma maior disposição em ver a ciência com um viés utilitário, como a retomada do controle e domínio da natureza que foi perdido pelo homem em decorrência de sua expulsão do Éden, após o pecado original.

No campo filosófico, a defesa do método indutivo por Francis Bacon reabilita a experiência sensível como forma validade de produzir conhecimento científico e de, consequentemente, assumir o poder de controlar os eventos da natureza. Nesse sentido, Stokes (2005, p. 60) aduz que "a moderna distinção entre ciência e tecnologia era considerada tênue no pensamento de Bacon e seus contemporâneos, que tendiam a identificar as duas. Na visão de Bacon, as técnicas eram conhecimento, mais que frutos do conhecimento".

Mas este casamento entre ciência e tecnologia proposto por Bacon demorou a se estabelecer. Na contramão de seu raciocínio, a separação entre a ciência e a tecnologia foi reforçada pelos arranjos institucionais durante a Modernidade. A ideia de que a ciência prepara o caminho para a tecnologia - que nos parece óbvia nos dias atuais - somente se solidificou a partir do Século XIX.

Até este período, a ciência pura era aquela que atraía o maior interesse dos intelectuais. Praticada como uma arte, continuou a ser desenvolvida somente por pessoas que dispusessem de recursos ou de patrocínio, contingenciada por um imperativo econômico: uma vez que buscava o conhecimento em si mesmo, não trazia significativo retorno econômico e sequer tinha nisto um objetivo. Deveria ser praticada enquanto uma espécie de altruísmo elitista para o engrandecimento civilizacional. 
O aperfeiçoamento da técnica - ou o neologismo tecnologia, com o qual se popularizou a partir de então -, ao seu turno, encontrava-se nas mãos dos engajados trabalhadores práticos, sustentados pelo retorno financeiro de seu ofício.

A Revolução Industrial foi o evento que definitivamente começou a erodir qualquer elitização do conhecimento científico em detrimento da técnica, aproximando-os na pirâmide da divisão social do trabalho e viabilizando a união em matrimônio de ambas as formas de racionalidade, tão segregadas até então. À moda dos arranjos nupciais das elites de época, este casamento não se deu senão por uma dose de interesses mútuos.

Até a aurora da Revolução Industrial, os conhecimentos praticados nas oficinas de manufatura do mercantilismo não eram essencialmente diferentes dos conhecimentos desenvolvidos ao longo da Idade Média pelas corporações de ofício. A figura do artesão é central em ambos os modelos econômicos, onde a produtividade enfrentava claros gargalos na capacidade humana de executar determinada tarefa. O conhecimento que fez nascer a sociedade industrial, que possibilitou o domínio da força mecânica através da máquina à vapor, se deve muito mais ao empirismo e trabalho árduo de tecnólogos - que buscavam na produção de bens de consumo para a satisfação de utilidades humanas uma forma de sustento - que a uma elite de cientistas que se encastelavam nas universidades para entender as formas de liberação da energia na natureza e suas leis de conservação.

Nessa esteira, Rosenberg (2006, p. 67-92) demonstra que foi o avanço da técnica, mais do que a ciência, que impulsionou a Revolução Industrial. O ganho de produtividade alcançado neste salto tecnológico - e consequente acúmulo de excedentes - substituiu a figura dos mestres artesãos dono de oficinas manufatureiras pelos ricos e poderosos burgueses industriais, líderes de um exército de operários. Assim, Rosenberg (2006, p. 67-92) aponta que para a teoria marxiana, o capitalismo seria um produto da Revolução Industrial e não sua causa.

A aproximação entre ciência e tecnologia começou a se fortalecer a partir do momento em que a pesquisa científica passou a preocupar-se com problemas reais que atravancavam o crescimento da produção industrial e na medida em que as respostas trazidas pela ciência fundamentavam o progresso tecnológico. A ciência realizada através da pesquisa prática, tornou-se, tal qual a técnica, uma forma de gerar renda para o sustento ou enriquecimento do pesquisador, na medida em que o os cientistas verificam nela uma oportunidade de retorno financeiro pela venda de seu conhecimento à indústria. 
Não raramente, a pesquisa aplicada proporcionava um entendimento de fenômenos fundamentais da natureza que acreditava-se ser próprio da pesquisa científica pura. Para determe apenas num exemplo, destaco uma sucinta análise realizada por Stokes (2005, p. 31) acerca das motivações científicas que impulsionaram a carreira de Pasteur e foram determinantes para o surgimento da microbiologia no Século XIX:

Ninguém pode duvidar de que Pasteur buscava um entendimento fundamental dos processos de doença e de outros processos microbiológicos que ia descobrindo, à medida que se movia pelos estudos sucessivos de sua notável carreira. Mas também não existe dúvidas de que ele buscava tal entendimento para alcançar os objetivos aplicados de prevenir a deterioração na produção de vinagre, cerveja, vinho e leite, e de vencer a flacherie no bicho-de-seda, o antraz no gado ovino e bovino, a cólera no frango, e a raiva em animais e seres humanos.

Este foi o espírito que impulsionou a Segunda Revolução Industrial. A articulação entre ciência e tecnologia possibilitou avanços inimagináveis, tais como uma série de desenvolvimentos dentro da indústria química, elétrica, do petróleo e do aço que firmou a indústria em um novo patamar.

Passaram a permitir ao inventor reclamar parte do retorno econômico decorrente da mudança tecnológica. Deter os meios de produção tornou-se mais recompensador que desenvolver técnicas e aperfeiçoar conhecimento.

Noutras palavras, a união entre ciência e tecnologia somente tornou-se possível em um contexto histórico no qual o domínio da natureza provou ser um insumo indispensável ao fortalecimento e expansão da atividade econômica, o que era reconhecido e incentivado pelo Estado através da ampliação do serviço público de formação científica e da regulamentação das Leis de Patentes. Com este regime legal, recompensava-se o financiamento e promoção privada da atividade inventiva com a oferta de direitos exclusivos de propriedade industrial, num processo que retroalimentava o poderio econômico das industrias através da contabilização patrimonial de ativos do conhecimento, bens imateriais decorrente da pesquisa, desenvolvimento e inovação.

Dessa forma, embora ambas as racionalidades - ciência e técnica - já tivessem florescido há milênios na inteligência humana, a interação entre ambas somente tornou-se próspera sob sistema capitalista. Não afirmo, com isso, que esta interação seja um fato histórico inédito. É certo que ela tenha ocorrido em civilizações ancestrais ou populações nativas de outra parte do globo e sob os mais diversos sistemas econômicos.

A distintividade desta interação no sistema capitalista, que pretendo aqui historicizar, é que ela se deu impulsionada por razões utilitaristas fiéis à melhor tradição baconiana que 
encontrou terreno favorável para frutificar - quase 300 anos após sua formulação filosófica devido à convergência de pelo menos cinco fatores que somente se fizeram simultaneamente presentes na história no momento peculiar do capitalismo que foi a Segunda Revolução Industrial: a) o ímpeto da acumulação do capital, traço distintivo do sistema capitalista; b) a tendência globalizante solidificada após o mercantilismo; c) a massificação dos meios de produção, através da máquina à vapor durante a Primeira Revolução Industrial; d) a ampliação do regime de propriedade privada para estendê-lo à exploração dos recursos naturais e às criações intelectuais e, por fim; e) a crescente ambição em dominar a natureza, no afã de tornar o homem cada vez menos suscetível às intempéries.

Entretanto, creditar o sucesso definitivo na interação entre ciência e tecnologia dentro do capitalismo somente à uma convergência conjuntural me parece uma hipótese um tanto ingênua. Há um outro fator determinante para assegurar a perenidade deste matrimônio. Precisa-se reconhecer que capitalismo - e a livre iniciativa que está em seu fundamento - foi avassaladoramente eficaz em entregar à sociedade muitas das promessas do desenvolvimento tecnológico, notadamente no que diz respeito à transformar recursos naturais em utilidades que tornaram a vida humana mais confortável e longeva em comparação às condições de nossos ancestrais. Esta eficácia se deu em tal monta que após dois séculos de aperfeiçoamento o mercado tecnológico se diversificou e crescentemente se tornou a matriz de toda a dinamização de mercado que distingue a economia do Século XXI.

Para além da satisfação de necessidades primárias com alimentação, saúde e educação, a população de todo o mundo confere às utilidades e dispositivos tecnológicos um papel tão fundamental que eles são responsáveis por abocanhar uma fatia cada vez maior do orçamento doméstico, seja para o lazer ou para tornar mais simples e fáceis diversas atividades do dia-a-dia. Já na indústria, o aperfeiçoamento de produtos, o aumento da produtividade e competitividade no mercado de consumo passaram-se a se fundamentar no próprio avanço tecnológico dos processos e ferramentas fabris, tornando a inovação tecnológica um processo endógeno.

Não podemos nos afastar da constatação de que o capitalismo é regido fundamentalmente pela lei econômica básica da oferta e da procura. Se o mercado de consumo não tivesse recebido de forma tão entusiasmada as novidades de bens e serviços crescentemente acessíveis pelo seu barateamento, num trinômio mercadológico - utilidade, 
oferta e acessibilidade - viabilizado a partir da interação entre ciência e tecnologia, estas inovações não teriam outra sorte senão serem deixadas de lado.

Aliás, deve-se pontuar que muitas inovações tecnológicas seguiram essa sorte e caíram em desuso, pois se mostraram falhas em atender um dos pontos deste trinômio mercadológico, não fornecendo o retorno financeiro que mantêm aberta a via de investimentos do capital. Entretanto, o sucesso de tantas outras tecnologias, que se sucedem dia após dia em novas gerações de dispositivos utilitários - que impulsionam e são impulsionados pela pesquisa científica - não deixam dúvidas de que o modelo econômico de interação entre a ciência e tecnologia se mostrou viável, economicamente sustentável apesar de seus elevados custos e riscos.

\section{A MILITARIZAÇÃO DO DESENVOLVIMENTO TECNOLÓGICO.}

Feitas as devidas observações sobre as determinantes circunstâncias históricas que possibilitaram o casamente entre a ciência e tecnologia, devo retomar a trilha histórica deste matrimônio que teve na Segunda Revolução Industrial apenas as suas núpcias.

O modelo industrial baseado em inovações tecnológicas e na multiplicação de ativos do conhecimento como forma de garantir competitividade no mercado continuou desenvolvendo-se progressivamente nos Estados Unidos e Europa até meados da década de 1910. No âmbito estatal, o fortalecimento de arranjos institucionais calcados na formação acadêmica e na regulamentação do regime de patentes seguiu estável, apoiando o desenvolvimento industrial com evidentes ajustes nas políticas nacionais decorrentes da experiência internacional em ambos os lados do Atlântico. Não obstante o inexorável avanço econômico e suas transformações sociais que marcam o período de transição do Século XIX ao Século XX, pode-se dizer quem em termos de políticas púbicas e regulamentações legais de fomento da ciência e tecnologia, pouco foram as transformações significativas.

A indústria armamentista não se furtou ao ritmo de progresso industrial então disseminado. Quando eclodiu a Primeira Guerra Mundial, o domínio de tecnologia para a fabricação de metralhadoras não era exclusividade de nenhuma das nações envolvidas no conflito. Este equilíbrio tecnológico inicial causou um verdadeiro impasse na frente de batalha. Com soldados armados e entrincheirados, era impossível para qualquer um dos lados avançar significativamente em direção ao inimigo sem ser alvejado. 
Inevitavelmente, as forças militares tiveram que recorrer à soluções tecnológicas para superar este impasse. Inovações como o tanque de guerra, o gás venenoso e a fotografia aérea foram decisivas para possibilitar o avanço de tropas e superar o "impasse das trincheiras". Outros aperfeiçoamentos na aviação, metalurgia e química encaminharam o conflito para o seu fim.

A experiência da guerra trouxe consigo a certeza de que o domínio da tecnologia, além de um poderoso insumo ao mercado, constituía-se um elemento importante para garantir a soberania e supremacia de uma nação frente aos seus adversários.

Assim - além dos já existentes arranjos institucionais de incentivo à inovação tecnológica, através da ampliação do sistema de educação para formação científica e da regulamentação das Leis de Patentes -, não tardou às autoridades nacionais concluírem pela crescente necessidade de manter um sistema de subvenção estatal direta e robusta para fomentar a pesquisa científica e desenvolvimento tecnológico em matérias estratégicas de segurança nacional.

Esta conscientização do determinante papel da dialética entre ciência e tecnologia enquanto fator central de uma crescente supremacia militar foi seriamente refletida por todas as nações - vitoriosas, derrotadas ou neutras em relação ao conflito.

Não pretendo afirmar, com isso, que a conscientização das vantagens que o melhoramento de armas e estratégias militares acarreta sobre os adversários possa ser considerada uma novidade que surgiu cenário na Primeira Guerra Mundial. Na verdade, o conhecimento da vantagem técnica sobre o adversário era fator sabidamente determinante de todos os conflitos civilizacionais da Antiguidade, Idade Média e Modernidade. Fato que pode ser considerado propriamente uma lição no contexto da Primeira Guerra Mundial é que, mais uma vez, a interação entre a técnica e a ciência possibilitou uma vantagem sem precedentes, que se superava a cada momento numa velocidade nunca antes experimentada. Portanto, tal como ocorreu nos processos fabris após a Segunda Revolução Industrial, o principal motivo a despertar o interesse militar sobres a inovações tecnológicas foi o ritmo com que as tecnologias passaram a se suceder no campo de batalha após a interação ente técnica e ciência.

\section{O INIMIGO COMUM: A CRISE AMBIENTAL.}


A indústria passou a ditar o objeto de estudo da ciência, pois que na lógica do mercado, é inteiramente natural permitir que considerações utilitaristas determinem os rumos para o qual a ciência deve desenvolver-se

A crise ambiental deixou claro que o capitalismo fracassou solenemente na principal promessa do desenvolvimento tecnológico: garantir o domínio da natureza para promover um bem-estar duradouro e sustentado, que traga saúde e segurança à vida humana. Quanto mais o homem concentrou-se no desenvolvimento do atual modelo econômico e na especialização do processo científico, mais desconectou-se do meio ambiente natural, gerando sérios riscos à própria existência da humanidade.

Atravessamos a iminência de uma catástrofe nuclear que nunca foi superada, apesar de encontrar-se adormecida nos noticiários. Desde o acirramento dos ânimos durante a Guerra Fria - que fez com que EUA e URSS produzissem uma quantidade de armamentos suficientes para definitivamente inviabilizar a vida como conhecemos no Planeta Terra - e mesmo após o seu término, com o temor do surgimento de um mercado negro de venda de armas nucleares para grupos terroristas e governos ditatoriais, ou ainda através da proliferação de usinas nucleares que não se mostraram fiáveis, gerando vazamentos radioativos constantes, o planeta vive em estado de alerta.

Mesmo pondo de lado esta ameaça, o planeta deu inequívocos sinais de que um desastre ecológico em grande escala, decorrente da poluição do ar, do solo, da água e dos alimentos pelos mais diversos produtos químicos, alteraria as estruturas do meio-ambiente de uma forma nuca antes vista desde que a raça humana surgiu.

O ponto comum entre a ameaça nuclear e demais formas de poluição da água, do solo, do ar e dos alimentos é que ambas são resultantes exclusivamente da ação tecnológica humana sobre o meio ambiente natural, que ao longo dos últimos séculos têm levado o ecossistema à limites extremos, que põe em cheque a sua capacidade de resiliência.

Esta deterioração do meio ambiente tem igualmente arruinado o estado de saúde das pessoas. Proliferam-se nos países desenvolvidos as chamadas "doenças da civilização", enfermidades crônicas e degenerativas tais como doenças cardíacas, câncer, AVC, obesidade, mal de Parkinson e Alzheimer. Enquanto isso, os países subdesenvolvidos e em desenvolvimento sequer conseguem deter a insegurança alimentar e as mais comezinhas doenças infecciosas, decorrentes da falta de estrutura mínima em saneamento básico, distribuição de água potável e investimentos em saúde preventiva. 
A deterioração do meio ambiente social, em todo o mundo, tem ainda gerado um quadro psicológico epidêmico: depressão, síndrome do pânico, transtorno bipolar, esquizofrenia e outros distúrbios de comportamento atingem cada vez mais pessoas, sem qualquer indicativo de que essa proliferação possa regredir.

Paralelamente, o aumento da violência urbana, verificada no crescimento da criminalidade, acidentes de trânsito e mortes violentas, fazem dos jovens as principais vítimas, gerando um alto custo social. Ultimamente, o terror e o fundamentalismo têm gerado grande comoção social, mostrando que a humanidade não conseguiu superar suas diferenças étnicas e religiosos, apesar de todos os esforços pela paz mundial.

São incontáveis os estudos, em todas as áreas, a apontar a conclusão de que, quanto mais pobre é uma população, mais degradado é meio-ambiente em que ela vive, decorrendo no maior agravamento de seus problemas sociais, propagando mais miséria e mais degradação, num eterno ciclo vicioso.

Como já dito, este cenário caótico global e a poluição atingem também o bem público mais precioso do planeta. $\mathrm{O}$ acesso a água potável é essencial à manutenção da vida humana e da quase a totalidade de outros seres vivos que habitam o planeta. Sem o seu regular fornecimento não se pode garantir a sobrevivência de todos os organismos vivos e o bom funcionamento dos ecossistemas, comunidades urbanas e da economia global.

Entretanto, à medida que a população humana cresce, as atividades agrícolas e industriais se expandem, fazendo com que o uso de água potável se multiplique, tornando este bem cada vez mais precioso. Paralelamente, as recentes mudanças climáticas ameaçam alterar o ciclo hidrológico global, gerando transformações ainda imprevisíveis ao futuro da humanidade.

Parece irônico que tenhamos conseguido tornar a exploração aeroespacial parte do nosso dia-a-dia, fazendo do lançamento de satélites à órbita terrestre uma atividade corriqueira, enquanto os governos não conseguem impedir que muitos países pobres, sobretudo do continente africano e do oriente, atravessam sérias crises hídricas. No mundo desenvolvido, o temor do desabastecimento tem feito políticos refletirem seriamente sobre a regulamentação de seu uso e a prevenção do desperdício. 
A ONU estima que um bilhão de pessoas carece de acesso a um abastecimento de água suficiente, definido como uma fonte que possa fornecer 20 litros por pessoa por dia a uma distância não superior a mil metros ${ }^{4}$.

Cecília Polacow Herzog (2013, p. 87) aponta que:

Consumimos mais do que podemos produzir; emitimos mais GEE do que o sistema vegetal é capaz de processar, alterando a dinâmica do sistema climático do planeta; eliminamos mais ecossistemas e florestas do que é possível regenerar. Poluímos tanto que não estamos conservando nossas fontes de ar, águas e solo fértil. O ecossistema terrestre corre sério risco de perder a resiliência e mudar de patamar. Poderá passar a funcionar de outra maneira, chegando a se tornar extremamente hostil para manter a vida humana na Terra.

Assim, apesar de toda ação humana predatória, o planeta poderá atravessar mudanças climáticas sérias, mas resistirá. O que corre verdadeiro risco é a vida humana, que poderá ser extinta em decorrência de suas próprias ações, levando consigo algumas outras espécies de animais e seres-vivos.

\section{CONSIDERAÇÕES FINAIS}

Conforme se pode depreender diante do estudo percorrido, a economia da inovação tecnológica encontrou terreno para se desenvolver e prosperar por ter conseguido realizar boa parte das promessas da modernidade. Contudo, a crise ambiental deixou claro que fracassamos miseravelmente em garantir o domínio da natureza para promover um bem-estar duradouro e sustentado.

Tal fracasso não pode ser colocado para baixo do tapete, como pretendem alguns teóricos negacionistas, uma vez que possui capacidade de comprometer a continuidade da própria vida humana.

Assim, cabe às ciências jurídicas também se debruçar sobre o tema e buscar alternativas. Algumas problematizações que propomos são: Existe uma moral inerente à inovação? A inovação tecnológica ainda é capaz de promover o desenvolvimento sustentável? O estado regulador deve intervir nas políticas de incentivo para orientar os tipos de inovação a sociedade deve perseguir? O desenvolvimento tecnocientífico deve ser perseguido a qualquer custo? Como devemos lidar com os riscos do desenvolvimento?

Estas são questões que buscamos instigar ao longo do estudo proposto e que esperamos, possam trazer aportes a enriquecer o debate jurídico a respeito do tema.

\footnotetext{
4 Informação disponível no sítio eletrônico da ONU, em <https://nacoesunidas.org/acao/agua/> Acesso em 20/07/2016.
} 


\section{REFERÊNCIAS BIBLIOGRÁFICAS}

ADEODATO, João Maurício. Bases para uma metodologia da pesquisa em direito. Brasília: Centro de Estudos Jurídicos (CEJ), 1998. Disponível em: www.cjf.jus.br/revista/numero7/artigo17.htm acesso em 02 de maio de 2008.

ARAÚJO, Bruno C. Incentivos fiscais à pesquisa e desenvolvimento e custos de inovação no Brasil. Radar: tecnologia, produção e comércio exterior, v. 9, p. 3-11, 2010.

ARISTÓTELES. Metafísica II. Texto grego com tradução ao lado a cura de Giovanni Reale. Trad. Marcelo Perine. Edições Loyola: São Paulo, 2002.

BARBOSA, Denis Borges. Direito da inovação: comentários à lei n.10/973/04, lei federal da inovação. Rio de Janeiro: Editora Lumen Juris, 2006. p. 01.

O Direito Constitucional da Inovação. Disponível em: <http://denisbarbosa.addr.com/inovaconst.pdf $>$. Acesso em 18/11/2012.

. Uma introdução à propriedade intelectual. 2. ed., Rio de Janeiro: Lúmen Júris, 2003.

BARROSO, Luís Roberto Interpretação e aplicação da Constituição. São Paulo: Saraiva, 2002.

Curso de Direito Constitucional Contemporâneo: os conceitos fundamentais e a construção do novo modelo. $2^{\text {a }}$ ed. São Paulo: Saraiva, 2010.

BASTOS, Valéria Delgado. 2000-2010: uma década de apoio federal à inovação no Brasil. Revista do BNDES, Rio de Janeiro, n. 37, p. 127-175, 2012.

BERCOVICI, Gilberto. Desigualdades regionais, Estado e Constituição. São Paulo: Max Limonad, 2003.

Constituição Econômica e Desenvolvimento: uma leitura a partir da Constituição de 1988. São Paulo: Maleiros, 2005.

COMPARATO, Fábio Konder. A Afirmação Histórica dos Direitos Humanos. São Paulo: Saraiva, 1999.

DE NEGRI, João Alberto; LEMOS, Mauro Borges. Avaliação das políticas de incentivo à P\&D e inovação tecnológica no Brasil. 2009. Disponível em: < http://repositorio.ipea.gov.br/handle/11058/5822> Acesso em 05/06/2016. 
DWORKIN, Ronald. Levando os Direitos à sério. (Trad.) Nelson Boeira. São Paulo: Martins Fontes, 2002.

2000.

Uma questão de princípio. (Trad.) Luis Carlos Borges. São Paulo: Martins Fontes,

FREITAS, Carlos Cesar Garcia; MAÇANEIRO, Marlete Beatriz; KUHL, Marcos Roberto; SEGATTO, Andrea Paula; DOLIVEIRA, Sergio Luis Dias; LIMA, Luiz Fernando de. Transferência tecnológica e inovação por meio da sustentabilidade. in Revistada Administração Pública. Vol. 46(2): 363-384, ILUS, TAB. 2012.

GANDELman, Marisa. Poder e Conhecimento na Economia Global. Rio de Janeiro: Civilização Brasileira, 1994.

GRAU, Eros Roberto. A Ordem Econômica da Constituição de 1988. São Paulo: Malheiros, 2003.

Elementos de Direito Econômico. São Paulo: Revista dos Tribunais, 1981.

IPEA. Radar: tecnologia, produção e comércio exterior. n. 1 (abr. 2009). Brasília: Ipea, 2009. Disponível em: < http://superaparque.com.br/upload/20151005-041038-incentivosfiscais.pdf $>$ Acesso em 05/06/2016.

KANNEBLEY JR, Sergio; PORTO, Geciane. Incentivos Fiscais à Pesquisa, Desenvolvimento e Inovação no Brasil. 2012. Disponível em: <http://superaparque.com.br/upload/20151005-041038-incentivos-fiscais.pdf> Acesso em 05/06/2016.

MATIAS-PEREIRA, José. A gestão do sistema de proteção à propriedade intelectual no Brasil é consistente? in Revistada Administração Pública. in Revistada Administração Pública. Vol. 45(3). pp. 567-590, Rio de Janeiro : Maio/jun. 2011

KRUGLIANSKAS, Isak. Gestão de inovação: a lei de inovação tecnológica como ferramenta de apoio às políticas industrial e tecnológica do Brasil. RAE electron. [online]. 2005, vol.4, n.2, pp. 0-0. ISSN 1676-5648

MOWERY, David c.; ROSENBERG, Nathan. Trajetórias da inovação: a mudança técnica nos Estados Unidos da América no século XX. Campinas: Editora Unicamp, 2005.

NELSON, Richard R. As fontes do crescimento econômico. Campinas: Editora Unicamp. 2006.

NUSDEO, Fábio. Desenvolvimento e ecologia. São Paulo: Saraiva. 1975. 
OCDE. Manual de Frascati. Metodologia Proposta para Definição da Pesquisa e Desenvolvimento Experimental. Versão 2013. Disponível em: <http://www.mct.gov.br/upd_blob/0225/225728.pdf>. Acesso em 20/12/2015.

Manual de Oslo. Proposta de Diretrizes para Coleta e Interpretação de Dados sobre Inovação Tecnológica. <http://www.mct.gov.br/upd_blob/0225/225728.pdf>. Acesso em 20/12/2015.

OECD environmental outlook (2020). Paris, OECD publications service, 2001. Disponível em: <http://www.oecd.org>. Acesso em: 12 mai. 2005.

PALMA, Mário S. YAMANE, Tetsuo. CAMARGO Antonio C. M. Camargo. Biodiversidade: preservação e bioprospecção. In: Biodiversidade Valor Econômico Valor Social. SBPC/Labjor, 2001. Disponível em: http://www.comciencia.br/reportagens/ biodiversidade/bio13.htm

PIAIA, T. C. Lei da inovação e a gestão da transferência de tecnologia: desafios para uma sociedade multicultural. 2015. 177f. Dissertação (Mestrado em Direito) - Universidade Regional Integrada Do Alto Uruguai e das Missões, Santo Ângelo, 2009. Disponível em: $<$ http://www.dominiopublico.gov.br/download/teste/arqs/cp116044.pdf $>$ Acesso em $16 / 12 / 2015$.

RODRIGUES, Silvio. Direito Civil: Direito das Coisas. V. 5. 28. ed. São Paulo: Saraiva, 2003.

ROSENBERG, Nathan. Por dentro da caixa preta: tecnologia e economia. Campinas, SP: Unicamp, 2006.

SCHUMPETER, Joseph A. Teoria do Desenvolvimento Econômico. Coleção Os Economistas. São Paulo, Nova Cultural, 1997.

SHERWOOD, Robert M. Propriedade intelectual e desenvolvimento econômico. Tradução de Heloísa de Arruda Villela. São Paulo: Editora da Universidade de São Paulo, 1992.

STAL, Eva. Inovação tecnológica, sistemas nacionais de inovação e estímulos governamentais à inovação. In: MOREIRA, Daniel Augusto; QUEIROZ, Ana Carolina S. (coord). Inovação organizacional e tecnológica. São Paulo, Thomson Learning, 2007.

STOKES, Donald E. O Quadrante De Pasteur: a ciência básica e a inovação tecnológica. Tradução de José Emílio Maiorino. Campinas: Editora da UNICAMP, 2005.

VIGgiani, T. S. A Experimentação Animal Nos Contratos De Pesquisa E Desenvolvimento Entre Indústrias Farmacêuticas E Universidades Públicas. 2015. 157f. Dissertação (Mestrado em Direito) - Faculdade de Direito da Universidade de Marília, 
Marília, 2015. Disponível em: <http://www.unimar.br/pos/trabalhos/arquivos/ F58D237C24960D09045A1CD1BC425522.pdf> Acesso em 16/12/2015. 